\title{
LÍRICA NO TEATRO DO ABSURDO E ÉPICA EM BRECHT: A IMPORTÂNCIA DOS GÊNEROS LITERÁRIOS NA ANÁLISE TEATRAL.
}

\author{
Maurini de Souza Alves Pereira
}

\begin{abstract}
Jornalista, Mestre em Literatura pela UFPR e Doutoranda em Lingüística pela UFPR. Professora do Departamento Acadêmico de Comunicação e Expressão da UTFPR, campus Curitiba.
\end{abstract}

\begin{abstract}
Resumo: Contemporâneo à ultima fase do dramaturgo, teórico e diretor de teatro Bertolt Brecht, o Teatro do Absurdo apresentou-se como contraponto a sua obra, inserindo, na dramática, características do gênero lírico, em oposição ao hibridismo épico proposto e trabalhado por Brecht. Essa diferença se estabelece como fator essencial para a análise de tais correntes.
\end{abstract}

Palavras principais: teatro, teatro do Absurdo, Bertolt Brecht, hibridismo, gêneros literários.

Martin Esslin apresenta um enfoque especial sobre o teatro do absurdo, assinalando que

\begin{abstract}
Enquanto que os naturalistas e Brecht concentram-se na realidade social, no mundo exterior, outros autores dramáticos, seguindo o exemplo de Strindberg e também o de romancistas de estados oníricos, tais como Kafka e Joyce, voltaram-se para a representação do mundo da fantasia e do sonho. (...) O teatro de Brecht luta no sentido de encontrar o modo épico da poesia, o teatro do absurdo tende para o modo lírico. (ESSLIN,1978:71)
\end{abstract}

Conceito que ratifica em sua obra Teatro do Absurdo, em que apresenta como busca dessa escola "a concentração e a profundidade numa composição essencialmente lírica e poética" (ESSLIN, 1968:350). Apesar de admitir existirem traços líricos "em todo drama", vê o Absurdo como um caso à parte, por abrir mão de características comuns na dramática, como um enredo ou a situação no tempo, utilizando a estrutura formal apenas como "um recurso para expressar uma complexa imagem total", e apresentando todo o tempo da narrativa como "um só instante" (ESSLIN, 1968:350). Outros autores também apresentam o lirismo como componente fundamental para o teatro de Ionesco, Beckett, Adamov e Genet, como é o caso de Paulo Francis, que reconhece como ambição dos autores a subjetividade, ou seja, o relacionamento de "suas abstrações lingüísticas à essência de nossa condição humana, como a experimentamos como indivíduos[1]", ou Leo Gilson Ribeiro, que o apresenta como o teatro da abstração, em que o espaço vazio do palco "simboliza o vazio da alma de seus personagens e por extensão da humanidade hodierna" (RIBEIRO, 1965:160), assim como os espaços pobres e feios também retratam o interior humano.

Tendo Kafka como inspirador, essa corrente teve suas grandes produções praticamente concentradas na década de cinqüenta, e Paris como sede para o desempenho artístico. Para os dramaturgos do Absurdo, a comunicação entre os seres humanos tornou-se inútil, aparentemente impossível - apesar de lonesco 
defender que seu teatro mostra a dificuldade da comunicação, e não sua impossibilidade. Ele mesmo afirmou, porém, que a sociedade não pode resolver os maiores problemas do homem, como a tristeza humana, agonia de viver, medo da morte ou sede do absoluto[2], o que aponta para a inutilidade das relações sociais, opondo-se, por exemplo, a Bertolt Brecht, que concentrou toda a sua produção, inclusive lírica, nesse ponto. Essas características, a agonia, o medo, a tristeza, são despejados no palco, como um poema lírico, em que o autor expressa o interior, sem ordem de entrada, sem personagens profundos, sem leis de unidade, sem sequer situá-lo no tempo ou no espaço - uma característica recorrente nas peças é elas terminarem da mesma forma que iniciaram. Como resume Martin Esslin:

Porque o Teatro do Absurdo projeta o mundo pessoal do autor, faltam-lhe personagens objetivamente válidos. Não lhe é possível mostrar o embate dos temperamentos opostos ou estudar as paixões humanas em conflito, não sendo portanto dramático no sentido aceito da palavra. Nem lhe interessa contar uma história para transmitir alguma lição moral o social, como se propõe o teatro 'épico' e narrativo de Brecht. A ação de uma peça do Teatro do Absurdo não pretende contar uma história, mas comunicar uma configuração de imagens poéticas. (ESSLIN, 1978:349)

Sem esquecer que esse autor projetado é contemporâneo da última fase de Brecht e, na totalidade dos casos, um homem que atravessou duas guerras mundiais. Enquanto, porém, nos anos cinqüenta, o dramaturgo alemão, na época mais diretor que autor, encenava peças que compusera no exílio, como O círculo de giz caucasiano, em que as inserções líricas falam de lealdade, preocupação com o outro e um mundo melhor, governado sob a justiça do povo, o escritor do absurdo pensava nos efeitos da guerra nuclear e o nada a que ela levaria, afinal, o período era de guerra fria. A idéia de que o mundo poderia explodir a qualquer instante era comum e atingia a todos; daí a subjetividade dos textos apresentar o um "eu lírico" que poderia ser qualquer pessoa do planeta.

A o se deparar, por exemplo, com os personagens de Esperando Godot, de Becket $[3]$, é inevitável a pergunta: Quem são eles? Seremos nós? Eles fazem parte do conjunto de metáforas que rodeia a peça, e suas falas são tão importantes quanto os silêncios, apontados nas rubricas, que as separa. Como o verso ou a música da poesia. Se um protagonista for exigido, ele será tão abstrato (ou absurdo) quanto todo o trabalho: a espera ou esperança é o que fala o tempo inteiro. Não a esperança brechtiana, a nível social, de que o povo oprimido iria dominar, mas a interior, "última que morre", expressa na poeticidade de um sapato que hoje está apertado e amanhã "serve direitinho" (p.131); da árvore, hoje seca e amanhã cheia de folhas; do sol que vai se por, da lua que nascerá, da possibilidade de serem salvos; de terem uma corda amanhã; da fala: "Talvez hoje à noite possamos dormir na casa dele, no quentinho, no seco, de barriga cheia, na palha. Vale ou não vale a pena esperar por tudo isso?"

Qualquer motivo, como a chegada de Pozzo cego e Lucky mudo, no segundo ato, é suficiente para reacender a chama da espera: 
Vladimir: Não estamos mais sozinhos, esperando a noite, esperando Godot, esperando a espera. Nós lutamos sozinhos durante toda a tarde, sem apoio. Mas isso terminou. O amanhã já chegou. (...) O tempo já voa. O sol vai se pôr, a lua nascerá e nós iremos embora daqui.(p.148)

Não é à toa que Esperando está ao lado de Godot. Ou melhor, à frente dele. É título, é tema. E o "eu lírico" autor, ciente da associação entre espera e tempo, aponta inclusive para sua subjetividade quando isola as seguintes falas:

(longo silêncio)

Vladimir: Deu para passar o tempo.

Estragon: Teria passado de qualquer forma.

Vladimir: Sim, mas não tão depressa.

(Pausa) (p.85)

Aliás, são tão constantes as rubricas do tipo: "pausa", "longo silêncio", "silêncio", que essa característica - a não fala, está mesclada ao texto durante o tempo inteiro, o que remete a uma observação de Peter Szondi: "Quando não há mais nada a dizer, quando algo não pode ser dito, o drama emudece. Mas na lírica mesmo o silêncio se torna linguagem" (SZONDI, 2001:50).

Outro ponto a se destacar é o lirismo isolado de cenas e de algumas falas. Esslin aponta a seguinte passagem do segundo ato como "provavelmente a passagem mais lírica e mais bem escrita da peça" (ESSLIN, 1968:53)

Vladimir: É verdade, somos inexauríveis.

Estragon: É para não pensar.

Vladimir: Temos essa desculpa.

Estragon: É para não ouvir.

Vladimir: Temos esse motivo.

Estragon: Todas as vozes mortas.

Vladimir: Fazem um ruído de asas.

Estragon: De folhas.

Vladimir: De areia.

Estragon: De folhas

(silêncio)

Vladimir: Falam todas ao mesmo tempo.

Estragon: Cada uma para si.

(Silêncio)

Vladimir: Talvez sussurram.

Estragon: Murmuram.

Vladimir: Cochicham.

Estragon: Murmuram.

(Silêncio)

Vladimir: O que é que dizem?

Estragon: Falam de suas vidas.

Vladimir: Viver não foi bastante.

Estragon: Tem que falar da vida.

Vladimir: Morrer não foi bastante.

Estragon: Não é o suficiente.

(Silêncio.)

Vladimir: Fazem um ruído de plumas.

Estragon: De folhas.

Vladimir: De cinzas.

Estragon: De folhas.

(Longo silêncio) (p.115) 
Brecht assistiu a uma apresentação de Esperando Godot, e um dos projetos que não conseguiu concretizar foi o de escrever uma resposta a essa peça, que seria a ligação concreta entre seu projeto épico social para a transformação do mundo com a corrente do absurdo, lírica, individual e desiludida.

O conteúdo existente entre os medos da vida e o pavor da morte são o impulso para a obra de Ionesco, outro autor que marcou seu nome como poeta do Absurdo. Como um dos oponentes mais enfáticos do engajamento político-social de autores como Brecht, a quem criticou duramente em várias oportunidades, o romeno-francês defendia a arte como simples expressão do eu:

\footnotetext{
Para descobrir o problema fundamental comum a toda a humanidade, tenho de indagar qual é o meu problema fundamental, qual o meu medo mais inerradicável. Poderei então, com certeza, identificar os problemas e os medos de todas as pessoas, sem exceção. Tal o verdadeiro caminho para a minha própria escuridão, para a nossa escuridão, que tentarei conduzir até a luz do dia... Uma obra de arte é a expressão de uma realidade incomunicável que se tenta comunicar - e que por vezes pode ser comunicada. Esse é o seu paradoxo e sua verdade. $[4]$
}

Essa base subjetiva criou uma obra com sabor de agonia, em que o palco cheio, com muitos figurantes, transmite a angústia do homem que vive em um mundo lotado, mas sem perspectiva de se fazer entender por ninguém.

Bérenger é um exemplo desse homem. Que fala muito, mas não se comunica. $\mathrm{N}$ o início de $O$ Assassino, ou $O$ assassino sem recompensa, peça de três atos, considerada "não só sua obra mais ambiciosa como também a melhor"[5], já demonstra esse problema. O diálogo entre Bérenger e o Arquiteto (que também é Comissário, Clínico Geral, Psicanalista e Sociólogo) é, em boa parte, dois monólogos. No começo, Bérenger elogia a obra da "cidade radiosa" e o Arquiteto, com um misto entre orgulho por sua obra e resignação de funcionário eficiente, responde a esses elogios com explicações sobre o local. O diálogo começa a ser posto a prova quando o telefone do Arquiteto toca, e apesar dele atender e conversar com quem havia ligado, Bérenger continua falando, em reflexões líricas como:

Bérenger (continuando o monólogo): Dever ter sido desde... desde não sei quando... desde há muito, muito tempo... (O Arquiteto torna a meter o auscultador na algibeira e novamente dá sinais de impaciência; vai aos bastidores, à esquerda, traz uma cadeira que instala no canto, à esquerda, onde se supunha que estivesse a estufa.)... Deve haver séculos... ou talvez apenas alguns anos, ou talvez fosse ontem.... (IONESCO, 1963:129)

Quando o Arquiteto explica que há poucos moradores no bairro e que muitos estão se mudando de lá porque há um serial killer à solta, que mata as pessoas em um poço, atraindo-as sob o pretexto de lhes mostrar uma fotografia "do coronel", o diálogo passa a representar o terror de Bérenger contrastando com a paciência e conformação de seu informante - o primeiro tenta em vão mostrar o perigo que o 
assassino representa, enquanto o segundo pretende acalmá-lo, mostrando a situação como normal. Ambos sem sucesso. A comunicação foi inútil.

N o segundo ato, Bérenger chega em casa e é aguardado por seu amigo Eduardo. Antes porém, o que reflete uma característica recorrente na obra de Ionesco, conversas entre várias pessoas, falas repetidas ou canções são apresentadas, simultaneamente, no palco, misturando-se às vezes, criando uma aparência de caos em ritmo de canção popular:

(...)

O segundo velho: Outrora, outrora...

O primeiro velho: Por vezes ainda os vê?

O merceeiro (saindo da loja da frente, com ar furioso, olha para a janela do primeiro andar): Eh, minha senhora!

O segundo velho: Ah! Meu caro, já não há dessa gente que brilha... (vemo-lo desaparecer pela direita, ouvimo-lo) foi-se. Hoje só conheço dois... dessa gente brilhante...

O merceeiro: Eh, minha senhora! Por quem me toma?

Voz do segundo velho: ... dó dois. Um reformou-se, o outro faleceu!

(O primeiro velho desaparece também)

Merceeiro (mesmo jogo): Não... mas por quem me toma, minha senhora?

Voz do vagabundo (cantando): O capitão da corveta-a ...(IONESCO, 1963: 191-192)

$(\ldots)$

O caos da vida e a morte. A forma utilizada por lonesco para representar seu conflito interior sobre esse assunto é comparada, por Esslin à poesia ou música:

Não há descrição clínica que seja capaz de transmitir o que é que uma pessoa sente, por exemplo, quando está apaixonada. Um jovem pode ter ouvido falar, pode pensar que sabe como é que vai ser, mas quando chega realmente a ter e experiência irá compreender que o mero conhecimento intelectual do assunto não constituía conhecimento algum, no sentido verdadeiro. Um poema ou uma música, por outro lado, podem transmitir, mesmo que seja de forma limitada, a realidade do sentimento e da experiência. Da mesma forma, numa peça como Tueur Sans Gages lonesco não está como pensaram alguns críticos, tentando informar-nos, em três longos atos, que a morte é inevitável, mas tentando fazer-nos experimentar com ele qual é a sensação sentida quando se está a braços com essa experiência humana básica. (ESSLIN, 1968:172-173)

Bérenger também exprime a "sensação sentida" pela inutilidade da comunicação em $O$ rinoceronte. Apesar de possuir um enredo mais situado que $O$ assassino, a vida e o caos estão intrinsecamente ligados durante grande parte do texto, não sendo melhores ou piores opções que a solidão e a morte. Quando Bérenger explica a Jean que a razão de seu alcoolismo é não se sentir "à vontade na vida... no meio das pessoas", e reclama que a solidão the pesa, assim como a sociedade, ouve do amigo: "Você se contradiz. É a solidão que pesa ou é a multidão?", e conclui: "Viver é uma coisa anormal", sem conseguir comunicar com eficiência seu sentimento. Ionesco precisou de uma peça de quase três horas para transmitir o seu.

Ele idealizou sua peça a partir do depoimento do escritor francês Denis de Rougemont, que estava na Alemanha durante uma manifestação nazista, sentindo-se atingido e até seduzido pela histeria da população à sua volta, quando Hitler apareceu. Precisou unir forças para não se render ao delírio coletivo. Esse fato não faz de $O$ 
Rinoceronte uma peça política, ou, como escreveu a editora brasileira, "uma crítica a todo pensamento totalitário[6]"; Ionesco não gostava de Brecht e não acreditava no teatro político. O texto reflete o interior de um homem que se vê lutando todos os dias contra o inevitável, ou contra o que não vale a pena lutar: para que? Essa é a pergunta que se faz quando, na última fala da peça, Bérenger, sozinho, brada: "Sou o último homem, hei de sê-lo até o fim! Não me rendo". A inutilidade da luta do homem pela sobrevivência é o grito de lonesco, e se essa peça não possui falas tão líricas quanto Esperando Godot, seu argumento é tão subjetivo e desesperador quanto aquela. Esse desespero talvez seja a mola-mestre que tenha levado o escritor a buscar no gênero do "estado de alma particular [7]" um companheiro para a dramática.

Dentre outros, Martin Esslin aponta Bertolt Brecht como responsável por por escrever "uma série de peças que chegam muito perto do Teatro do Absurdo" [8], o que atribui à influência do cômico Karl Valentin, com quem Brecht trabalhou durante algum tempo. Valentin se destacou na utilização do clown e em sua obra se notam muitos traços seguidos pelos compositores de Paris da década de cinqüenta. Sua esquete Bahnhofszene[9], por exemplo, trata de uma senhora que chega na estação atrasada, perdendo o trem que a levaria à Itália; inconformada por não haver outro trem para o mesmo dia, após confundir Vesúvio com Vaticano e irritar sobremaneira o funcionário que a informava, ela começa a chorar e lamentar por seu marido que há catorze anos havia ido para a América do Sul e nunca mais voltado. O informante consola-a, dizendo que ele também havia ido para a América do Sul, só que há trinta anos, e que voltara, quando ela exclama, no dialeto bávaro utilizado por Valentin:

Frau: Oh, das war ein braver Mann, aber ein böser Mann - aber kommen tut er nicht mehr, mein Xaver.

Portier: So, Xaver hat er g'heißen, ich heiß auch Xaver.

Frau: So - ja, mein Xaver hat immer zu mir g'sagt: Wally, ich komm wieder, aber gekommen ist er nicht mehr.

Portier: Was, Sie heißen Wally?

Frau: Ja, Wally Rembremerdeng.

Portier: Und ich heiß Xaver Rembremerdeng.

Frau: Nein, ich heiß Rembremerdeng.

Portier: Und ich auch, und in Südamerika war ich auch.

Frau: Ja, bist Du der Xaver? Nein?

Portier: Und Du d'Wally?

Frau: Ja, Xaver!!! (Umarmt inn und wirft inm den Koffer auf den Fuß)

Portier: Ja, Rindvieh!!!

Frau: 30 Jahre haben wir uns nicht mehr gsehn, hast mich denn nimmer kennt?

Portier: Drum ist mir Dein Hut glei so bekannt vorkomma. (VALENTIN, 1961: 115-116)[10]

Tanto pela utilização das brincadeiras dos palhaços de circo quanto pelo contexto, o Teatro do Absurdo reproduziu essas situações (quase literalmente, no caso de $A$ cantora careca, de lonesco) e utilizou essa forma de comunicação com o público. Até que ponto a obra de Brecht seguiu a linha comum entre Valentin e o Absurdo, porém, deve ser fonte de questionamento. 
As peças apontadas por Esslin se encontram na primeira fase da obra de Brecht. São Homem é homem, com seu interlúdio, O filhote de elefante, Na selva das cidades e $O$ casamento. Na verdade, eles possuem alguns traços retomados posteriormente pelos autores do Absurdo, mas a base de seu trabalho era diferente.

E m O casamento ou $O$ casamento do pequeno burguês, por exemplo, peça curta, de um ato, há uma festa de casamento, em que a noiva está de cinco meses de gravidez, mas esconde dos convidados. Na verdade, o casamento foi conseqüência da gestação, e, sem ter dinheiro, o noivo construiu os móveis da casa nos seus períodos de folga:

A noiva: todos os dias, ele levantava as cinco horas da manhã para trabalhar!

(...)

O noivo: Não se pode confiar nos móveis que se compram nas lojas, são todos uma porcaria.

O marido: É uma boa idéia. Assim eles ficam fazendo parte de nós mesmos e tomamos mais cuidado (...) (BRECHT, 1990, 135)

Só que os móveis, feitos com cola barata, vão quebrando no decorrer da peça, sobrando somente a cama, cujo barulho de destruição se ouve quando acaba a comédia. Muito mais que simples móveis, dos quais a noiva comenta: "Foram parte de nós mesmos" (BRECHT, 1990, 142), o que vai desmoronando durante a festa é a aparência de casamento feliz, e dos relacionamentos, já podres, mas disfarçados com um exterior maquiado. Essa é a grande metáfora da peça, entremeada por outras, como a do fato do Marido, um dos convidados, esquecer a última música que ainda tinha em mente: antes do casamento, "ele tocava o tempo todo, mas depois que nos casamos, ele parou. Ele se dedica a me aborrecer. Antigamente, ele sabia uma porção de músicas, depois esqueceu um monte delas e cada vez sabia menos. Ele se perdia cada vez mais como se sofresse de um marasmo, e no fim ele ainda sabia só uma. Cante essa agora!" (BRECHT, 1990, 145), disse A Madame, sua mulher, mas não havia sobrado nenhuma, como o amor ou respeito em sua união.

Realmente, uma peça como $O$ casamento poderia ser tomada como uma antecessora do teatro do Absurdo, não fosse a diferença básica: Brecht não é subjetivo, não é lírico nesse trabalho. Pierre-Aimé Touchard, ao comentar o texto de Beckett, constata:

Se este diálogo nos sensibiliza tanto, é porque, na verdade, não se trata de um diálogo entre dois vagabundos, mas antes do diálogo íntimo que cada um de nós trava consigo mesmo, quando se sente dividido entre o medo e o desejo. O teatro, então, é apenas uma objetivação de nossos próprios debates. (TOUCHARD, 1970:18)

E como comentário sobre o Teatro do Absurdo:

As teorias do absurdo se desenvolveram ao mesmo tempo que cada um descobria a incomunicabilidade dos seres. Cada indivíduo gritava sua solidão diante de uma sociedade 
impotente e um céu em trevas (...) Sem dúvida, nunca antes, no curso da história, o teatro cumpriu com mais evidência a sua missão de revelador da angústia do homem. (TOUCHARD, 1970:83)

Brecht não está expressando seu interior, nem o de ninguém, mas criticando uma instituição, ou melhor, as instituições, já que a amizade também é posta em cheque. Se o comentário da editora Abril sobre a obra Os rinocerontes falha por desprezar-Ihe o lirismo, atribuindo-Ihe atitude crítico-social, incluir o texto brechtiano no contexto do Absurdo é lhe imputar um lirismo que não contém. Brecht, inclusive, explica as situações. Por exemplo, o Marido, em dado momento, tem uma explosão contra a Madame, expondo abertamente a falsidade de sua relação. Durante toda a festa, o pai tenta contar histórias desagradáveis de parentes e conhecidos já mortos ou distantes, mas é cortado pelas pessoas que não se interessam pelos "causos". No final, quando os convidados haviam ido embora, furiosos, ele explica: "Eu sempre achei que contar histórias que não dizem respeito a ninguém é bem melhor... Catástrofes! Eles não agüentam ficar sozinhos com eles mesmos".

O Teatro do Absurdo não se auto-explica. Como um poema, ele é a expressão d a interioridade, e as peças de Brecht, com suas características similares, mas insuficientes, ratificam a importância do estudo do hibridismo lírico nessa escola.

\section{REFERÊNCIAS BIBLIOGRÁFICAS}

BECKETT, S. Esperando Godot. Trad.: Flávio Rangel. São Paulo: Abril Cultural, 1976.

BRECHT, B. Teatro Completo. O casamento do pequeno burguês. São Paulo: Paz e Terra, 1990.

ESSLIN, M. Teatro do absurdo. Rio de Janeiro: Zahar, 1968.

ESSLIN, M. Uma anatomia do drama. Rio de Janeiro: Zahar, 1978.

HEGEL. A estética. Poesia VII. Trad. Álvaro Ribeiro. Guimarães Editores.

IONESCO. O Assassino. Trad.: L.N.Jorge. Lisboa: Editorial Presença, 1963.

RIBEIRO, L.G. Cronistas do Absurdo. Rio de Janeiro: José Álvaro, 1965.

SZONDI, Peter. Teoria do drama moderno (1880-1950) Trad. L. S. Repa. São Paulo: Cosac \& Naifi, 2001.

TOUCHARD, P.A . O teatro e a angústia dos homens.Trad.: P.P. de S. Madureira e B. Palma. São Paulo: Livraria Duas Cidades, 1970.

VALENTIN, K. Karl Valentin's Gesammelte Werke. Münch

[1] Paulo Francis, introdução à Esslin, M. Teatro do Absurdo. Rio de Janeiro: Zahar, 1968. p. 7

[2] IONESCO. Apud ESSLIN, M. Uma anatomia do drama. Rio de Janeiro: Zahar, 1978. p.114

[3] As citações dessa peça são retiradas de BECKETT, S. Esperando Godot. Trad.: Flávio Rangel. São Paulo: Abril Cultural, 1976.

[4] IONESCO. Apud. Esslin, M. Teatro do Absurdo. Rio de Janeiro: Zahar, 1968. p115

[5] Esslin, M. Teatro do Absurdo. Rio de Janeiro: Zahar, 1968. p. 156

[6] Prefácio da editora a IONESCO, E. O Rinoceronte. São Paulo: Abril Cultural, 1976. p. XVIII.

[7] Designação dada à lírica por Hegel (HEGEL. A estética. Poesia VII. Trad. Álvaro Ribeiro. Guimarães Editores)

[8] Esslin, M. Teatro do Absurdo. Rio de Janeiro: Zahar, 1968. p. 324 
[9] Cena da estação ferroviária.

[10] Senhora: Oh, era um bom homem, mas um homem brabo - mas não volta mais, meu Xavier. / Porteiro: Olha só, ele se chamava Xavier, e eu também me chamo Xavier./ Senhora: Sim, o meu Xavier sempre me dizia: Wally, eu volto, mas não voltou mais. / Porteiro: O que, a senhora se chama Wally? I Senhora: Sim, Wally Rembremerdeng / Porteiro: E eu me chamo Xavier Rembremerdeng. / Senhora: Não, eu me chamo Rembremerdeng. / Porteiro: $E$ eu também, e eu também estive na América do Sul./ Senhora: Sim, você é o Xavier? Não?/ Porteiro: E você é a Wally?/ Senhora: Sim, Xavier!!! (Abraça-o e derruba a mala sobre seu pé)/ Porteiro: Sim, sua vaca!!!/Senhora: Nós não nos víamos há 30 anos e você não me conhecia mais?/ Porteiro: Bem que o chapéu me pareceu familiar. (Trad. minha) 